\title{
Exposure to common respiratory bacteria alters the airway epithelial response to subsequent viral infection
}

\author{
Carla Bellinghausen ${ }^{1,2}$, Fahad Gulraiz ${ }^{1,5}$, Alexandra C. A. Heinzmann ${ }^{1}$, Mieke A. Dentener ${ }^{2}$, Paul H. M. Savelkoul ${ }^{1,3}$,
} Emiel F. Wouters ${ }^{2}$, Gernot G. Rohde ${ }^{2}$ and Frank R. Stassen ${ }^{1, *^{*}}$

\begin{abstract}
Background: Colonization of the airways with potential pathogenic bacteria is observed in a number of chronic respiratory diseases, such as COPD or cystic fibrosis. Infections with respiratory viruses are known triggers of exacerbations of these diseases. We here investigated if pre-exposure to bacteria alters the response of lung epithelial cells to subsequent viral infection.

Methods: Bronchial epithelial cells (BEAS-2B cells and primary bronchial epithelial cells) were exposed to heat-inactivated Haemophilus influenzae, Pseudomonas aeruginosa or Streptococcus pneumoniae and subsequently infected with respiratory syncytial virus (RSV), type 2 human adenovirus or influenza B. Levels of pro-inflammatory cytokines, viral replication and expression of pattern recognition receptors were determined in culture supernatants and/or cell lysates.

Results: Exposure of BEAS-2B cells to $H$. influenzae before and during RSV-infection synergistically increased the release of IL-6 (increase above calculated additive effect at 72 h: $56 \% \pm 3 \%$, mean \pm SEM) and IL-8 (53 \% $\pm 12 \%$ ). This effect was sustained even when bacteria were washed away before viral infection and was neither associated with enhanced viral replication, nor linked to increased expression of key pattern recognition receptors. $P$. aeruginosa enhanced the release of inflammatory cytokines to a similar extent, yet only if bacteria were also present during viral infection. S. pneumoniae did not enhance RSV-induced cytokine release. Surprisingly, adenovirus infection significantly reduced IL-6 release in cells exposed to either of the three tested bacterial strains by on average more than $50 \%$. Infection with influenza B on the other hand did not affect cytokine production in BEAS-2B cells exposed to the different bacterial strains.

Conclusion: Pre-exposure of epithelial cells to bacteria alters the response to subsequent viral infection depending on the types of pathogen involved. These findings highlight the complexity of microbiome interactions in the airways, possibly contributing to the susceptibility to exacerbations and the natural course of airway diseases.
\end{abstract}

Keywords: Bacterial-viral co-infection, Polymicrobial infection, Inflammation

\footnotetext{
* Correspondence: f.stassen@maastrichtuniversity.nl

${ }^{1}$ Department of Medical Microbiology, School of Nutrition and Translational

Research in Metabolism (NUTRIM), Maastricht University, Maastricht, The

Netherlands

${ }^{4}$ P.O. Box 5800, 6202AZ Maastricht, The Netherlands

Full list of author information is available at the end of the article
} 


\section{Background}

Infections of the respiratory tract are a major risk to patients with chronic respiratory diseases, such as chronic obstructive pulmonary diseases (COPD). The majority of acute exacerbations of COPD (AECOPD) is associated with an acute respiratory infection, with viral and/or bacterial pathogens being detected in more than half of all exacerbations [1, 2]. Experimental infections of COPD and asthma patients with human rhinoviruses (HRV) have moreover provided evidence for a causal relationship between an acute infection and the onset of symptoms characteristic for acute exacerbations in both diseases [3, 4]. Other viruses that are detected during AECOPD include respiratory syncytial virus (RSV), influenza viruses and adenovirus strains $[5,6]$.

Next to viral infection, also bacterial infections can be involved in the development of acute exacerbations. Among the bacterial species that are frequently detected during such episodes are strains of non-typeable (NT) Haemophilus influenzae, Pseudomonas aeruginosa and Streptococcus pneumoniae [1]. Importantly, colonization with these bacteria is also frequently observed in the stable state of the disease. Potential pathogenic microorganisms (PPMs) have been detected in approximately $25 \%$ of COPD patients during stable disease, even when rather insensitive culture-dependent techniques were employed [7-10]. Likewise, increased load of PPMs has also been described for other chronic lung diseases, such as asthma and cystic fibrosis [11-13].

Not only is bacterial colonization associated with an increased risk to develop an acute exacerbation, it is also associated with increased levels of inflammatory markers in the stable state [14-16]. Furthermore, pro-inflammatory cytokines, such as IL-6 and IL-8, have been shown to be elevated in the sputum of frequent exacerbators and during exacerbation [17]. Changes in IL-6 between stable state and exacerbation were found to be particularly pronounced, if the exacerbations were associated with a viral infection [17-19].

AECOPD associated with the detection of a combination of bacterial and viral pathogens have been reported to be particularly severe in terms of inflammation and decline in lung function [20]. Moreover, these events on average required longer hospitalizations [2]. Presence of both, potential pathogenic bacteria and viruses, during the same period of exacerbations have been observed in as much as 12 to $25 \%$ of AECOPD [21, 22]. When specifically looking at AECOPD associated with a positive culture of NT $H$. influenzae, almost half of the patients were also tested positive for at least one respiratory virus [23]. Considering these studies made use of rather insensitive conventional culturing techniques to detect bacteria, these numbers are most likely even underestimating the prevalence of simultaneous presence of bacteria and viruses.
Numerous studies have investigated how primary viral infections increase susceptibility to secondary bacterial infections, for example by disrupting epithelial barriers [24], increasing bacterial attachment or colonization [25-28], or modulating innate and adaptive immune responses [29-33]. On the other hand, consequences of a primary exposure to bacteria on the outcome of secondary viral infections have been less extensively studied [34]. Considering the substantial proportion of patients chronically colonized with bacteria, this concept might though less well understood - be equally important.

We therefore hypothesized that the response of airway epithelial cells to respiratory viral infections is influenced by pre-exposure to bacterial pathogens. In the present study we investigated how exposure to different respiratory bacteria influences the inflammatory response and susceptibility of respiratory epithelial cells to a secondary infection with respiratory syncytial virus (RSV), influenza $B$ virus and adenovirus.

\section{Methods \\ Cell culture}

BEAS-2B cells (ATCC CRL-9609) were cultured in RPMI1640 (life technologies, Carlsbad, USA) supplemented with $10 \%$ fetal bovine serum (FBS; Lonza, Basel, Switzerland). For experiments, BEAS-2B cells were used for up to 15 passages after cryopreservation (passage number 20 to 35). Culture flasks and multiwell plates were pre-coated with a mixture of bovine collagen $(30 \mu \mathrm{g} / \mathrm{ml})$, human fibronectin (10 $\mu \mathrm{g} / \mathrm{ml}$; both BD Biosciences, San Jose, USA) and bovine serum albumin (BSA, $10 \mu \mathrm{g} / \mathrm{ml}$, Sigma Aldrich, St Louis, USA). For experiments, BEAS-2B cells were seeded at $10^{5}$ cells per well in collagen/fibronectin-coated 48-well plates the day before the experiment. Cell layers were approximately 80-90\% confluent at the start of the experiment.

Primary bronchial epithelial cells (pBECs) were kindly provided by the Primary Lung Cell (PLUC) facility Maastricht University Medical Center + (MUMC+, Maastricht, The Netherlands). Lung tissue used for the isolation of pBECs was obtained from the Maastricht Pathology Tissue Collection (MPTC) and originated from tissue resected during lobectomies or pneumonectomies of patients who underwent surgery for lung cancer. Collection, storage and use of tissue and patient data were performed in agreement with the "Code for Proper Secondary Use of Human Tissue in the Netherlands" (http://www.fmwv.nl). The scientific board of the MPTC approved the use of materials for this study under code MPTC2010-019. PBECs were isolated from bronchus rings that were macroscopically free of cancer. Isolation, culture and characterization of cells was performed as previously described [35]. Epithelial character of the cells was confirmed by immunohistochemical staining for cytokeratins 5, 6, 8 and 17. Experiments were performed on cells isolated from seven donors. All donors 
(median age 67 years, range 55-78 years) were neversmokers or former smokers, and had not been diagnosed with COPD, cystic fibrosis or asthma.

For the seeding of pBECs, the methodology was adapted to account for different generation times of cells derived from different donors and to meet growth requirements of the primary cells. PBECs were seeded at $1.5 \times 10^{4}$ cells per well in pre-coated 24-well plates in B/D medium consisting of $50 \%$ DMEM (life technologies) and 50 \% Bronchial Epithelial Basal Medium (BEBM; Lonza), supplemented with bronchial epithelial growth medium (BEGM) singlequots (Lonza), and BSA (1.5 mg/ml, Sigma Aldrich). Experiments were started once cell layers reached approximately $80 \%$ confluence.

\section{Virus culture}

Virus strains were provided by the Dutch National Institute for Public Health and the Environment (RIVM, Bilthoven, the Netherlands).

RSV (strain A2) was propagated in Vero cells and concentrated by precipitation in polyethyleneglycol 6000 as described previously [36]. Influenza B (Yamagata lineage) were propagated in MDCKII cells. Human adenovirus 2 was propagated in HeLa cells.

The infectivity of viruses was quantified by determining the $50 \%$ Tissue Culture Infective Dose $\left(\mathrm{TCID}_{50}\right)$ using the Spearman Karber Method [37].

\section{Bacterial culture}

All bacterial strains used in this study were reference strains obtained from ATCC and were cultured at $37{ }^{\circ} \mathrm{C}$ and $5 \%$ $\mathrm{CO}_{2}$. NT H. influenzae (ATCC 49247) was cultured on Vitox-supplemented chocolate agar plates (Oxoid, Wesel, Germany). P. aeruginosa (ATCC 27853) and S. pneumoniae (ATCC 49619) were cultured on B/D Columbia blood agar plates (Becton Dickinson, Franklin Lakes, USA).

\section{Infection protocols \\ Preparation of inactivated bacterial suspensions}

Bacterial suspensions were prepared by adding several colonies of an overnight culture to RPMI-1640 medium. These suspensions were heat-inactivated at $65{ }^{\circ} \mathrm{C}$ for $1 \mathrm{~h}$. Inactivation was confirmed by plating out aliquots of the suspension on agar plates. Bacteria were then pelleted by centrifugation at $4500 \mathrm{x} \mathrm{g}$ for $10 \mathrm{~min}$, washed once with PBS and re-suspended in infection medium. The composition of the infection medium was dependent on the cell type and virus used. Stimulation and infection of BEAS-2B cells with bacteria in combination with RSV and adenovirus was performed in RPMI-1640 supplemented with $2 \%$ FBS (Lonza). For subsequent infection with Influenza B, bacterial suspensions were prepared in serum-free medium consisting of Minimal Essential Medium (life technologies) supplemented with $1 \mathrm{mg} / \mathrm{ml}$ proteose peptone, $0.1 \mathrm{mg} / \mathrm{ml}$
BSA, $0.2 \mathrm{mg} / \mathrm{ml}$ D-glucose monohydrate (all Sigma Aldrich, St Louis, USA) and $0.05 \%$ trypsin/EDTA (life technologies). For experiments on primary cells, infection medium consisted of $\mathrm{B} / \mathrm{D}$ medium supplemented with $\mathrm{BEGM}$ singlequots (both Lonza) except human epidermal growth factor and bovine pituitary extract. The turbidity of the bacterial suspensions was adjusted to $0.5 \mathrm{McFarland}$ (equivalent to approximately $1.5 \times 10^{8} \mathrm{cfu} / \mathrm{ml}$ ).

\section{Continuous stimulation}

Bacterial suspensions were further diluted 1:10 in infection medium. Cells were first stimulated with bacteria for $4 \mathrm{~h}$, and subsequently infected with the respective virus. For virus infection, culture supernatants were aseptically collected from each well and preserved while cells were exposed for one hour to diluted virus to yield a multiplicity of infection (MOI) of one. After this initial attachment period, cells were washed once with PBS and the original culture medium (including bacteria) was added to back the wells.

\section{Pre-exposure protocol}

Bacterial suspensions of 0.5 McFarland were prepared as described above. For stimulation of cells, $0.5 \mathrm{ml}$ of the bacterial suspension or control medium were added to each well. After $24 \mathrm{~h}$ of exposure, cell layers were washed with PBS and infected with RSV at an MOI of one. Virus particles were allowed to attach for $1 \mathrm{~h}$, after which unbound virus was aspirated, cells layers were washed with PBS and fresh medium was added to the wells.

Cell-free supernatants and cell lysates were collected 24,48 and $72 \mathrm{~h}$ after viral infection and stored at $-80{ }^{\circ} \mathrm{C}$ until use.

\section{ELISA}

Levels of IL-6 and IL-8 were determined using an enzyme linked immunosorbent assay (ELISA) according to the manufacturer's instructions (Ready-SET-Go, eBioscience, San Diego, USA). Lower limits of detection were $2.4 \mathrm{pg} /$ $\mathrm{ml}$ for IL-6 and $3.2 \mathrm{pg} / \mathrm{ml}$ for IL-8.

\section{Determination of RSV RNA copies}

Total RNA from cell lysates was isolated using the FavorPrep Tissue Total RNA purification kit (Favorgen, Pingtung, Taiwan). Remaining genomic DNA was degraded by DNase treatment (Ambion Turbo DNAfree, life technologies). For each sample, $500 \mathrm{ng}$ of total RNA was reverse transcribed using the iScript cDNA synthesis kit (BioRad, Hercules, USA). Real-time PCR was then performed on a MyIQ real-time PCR system (Bio-Rad) using the fol lowing primers: Forward 5' - TTTCCACAATATYTAAGT GTCAA-3'; Reverse 5' - TCATCWCCATACTTTTCTGT TA-3'. Viral RNA copy numbers were calculated by using a standard curve derived from in vitro transcribed RSV RNA. 


\section{Statistical analyses}

Statistical analysis was performed using Prism 5 (GraphPad, La Jolla, USA) and SPSS 22.0 (IBM, Armonk, USA). Data are presented as mean \pm standard error of the mean (SEM) of five to seven independent experiments. For better visualization of the synergistic effects, the additive effect of two pathogens is indicated as a dashed line in some graphs. This theoretical additive effect for a given combination of pathogens was calculated as the sum of cytokine levels of the individual infections. Statistical significance of bacterial and viral challenges, as well as interactions between the two, were determined using a two way analysis of variance (ANOVA) and a Bonferroni post-hoc analysis. To determine statistical significance of bacterial-viral interactions in primary epithelial cells, relative changes over the additive effect were calculated and tested for statistical significance using a one sample $t$-test. Differences in viral RNA copies and infectious particles were tested for statistical significance using a one-way ANOVA. In all cases, effects were considered statistically significant if $p<0.05$.

\section{Results}

$H$. influenzae and $P$. aeruginosa synergistically enhance the release of the pro-inflammatory cytokines IL- 6 and IL-8 during RSV infection

We first investigated if exposure to respiratory bacterial pathogens can alter the epithelial response to subsequent RSV infection. To this end, we made use of the immortalized bronchial epithelial cell line BEAS-2B, which is frequently used to study airway epithelial responses to pathogens and displays similar expression of pattern recognition receptors (PRRs) as primary bronchial epithelial cells [38]. BEAS-2B cells were stimulated with heat-inactivated preparations of NT H. influenzae, P. aeruginosa or S. pneumoniae. Four hours later, cells were additionally infected with RSV and secretion of IL-6 and IL-8 was monitored over a total period of $72 \mathrm{~h}$.

Exposure of cells to heat-inactivated $H$. influenzae or $P$. aeruginosa caused significant release of the proinflammatory cytokines IL-6 and IL-8, as did infection with RSV alone. When cells were first exposed to heatinactivated $H$. influenzae (Fig. 1a) or P. aeruginosa (Fig. 1b) and subsequently infected with RSV, IL-6 release was synergistically increased: Seventy-two hours after infection, experimentally determined values of IL-6 in the culture supernatants were on average increased by $56 \pm 3 \%$ (H. influenzae) or $46 \pm 9 \%$ (P. aeruginosa) compared to the sum of cytokines released by either bacteria or virus alone (indicated as bacteria + virus (theoretical), dashed line). For S. pneumoniae on the other hand, there was no significant interaction of bacteria and virus on the induction of IL- 6 release at any of the assessed time points (Fig. 1c). Of note, the cytokine response of BEAS$2 \mathrm{~B}$ cells to heat-inactivated pneumococci was clearly lower than the cells' response to the other two tested bacterial species and there was no significant effect of $S$. pneumoniae exposure on cytokine release (Fig. 1c, f).

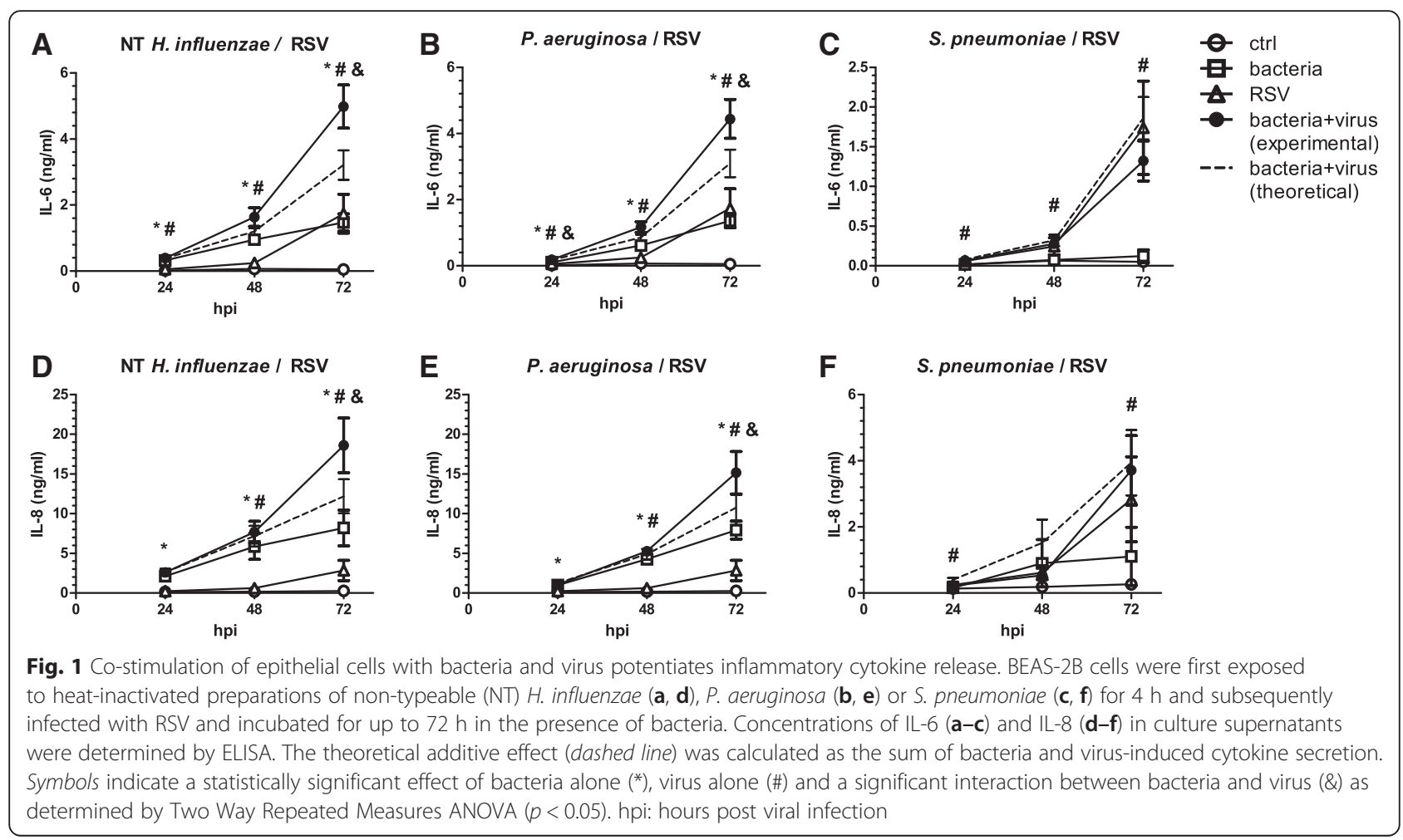


Similar to IL-6, also IL-8 release was synergistically enhanced in cells infected with RSV in the presence of either $H$. influenzae (Fig. 1d) or P. aeruginosa (Fig. 1e), whereas we did not detect a significant interaction of $S$. pneumoniae with this virus (Fig. 1f).

RSV and $H$. influenzae also synergistically increased IL-6 release when applied in the reverse order, i.e., when cells were first infected with RSV and subsequently co-stimulated with heat-inactivated bacteria, suggesting interactions between the two pathogens are not exclusive to primary bacterial stimulation (data not shown). However, since we were primarily interested in the effect of a primary bacterial exposure (as a model for bacterial colonization) on secondary viral infections, all results presented here are derived from experiments in which cells were first exposed to bacteria and subsequently infected with virus.

Stimulation with heat-inactivated bacteria and/or RSV did not significantly affect metabolic activity of the cells; differences in cytokine secretion were thus unlikely to be caused by pathogen-specific effects of the treatments on cell viability (Additional file 1: Figure S1A).

Due to the limited possibilities for bacterial control or clearance in our in vitro setting, inactivating the bacterial suspension was inevitable to avoid bacterial overgrowth of the epithelial cultures during the 3 day experimental period. To exclude any effect of the mode of inactivation on our readouts, we repeated the experiments using a low dose of gentamicin $(4 \mu \mathrm{g} / \mathrm{ml})$ to inhibit growth of $H$. influenzae, instead of heat-inactivating the bacteria. Although the results failed to meet statistical significance, we still observed a trend towards a synergistic interaction between $H$. influen$z a e$ and RSV on IL-6 release (mean increase $65 \% \pm 39 \%, p$ $=0.065$; Additional file 1: Figure S1B).

\section{Pre-exposure of cells to heat-inactivated $H$. influenzae is sufficient to synergistically increase RSV-induced cytokine release}

Several respiratory viruses, including RSV, have previously been shown to enhance attachment of a variety of bacterial species to cells of the respiratory tract $[27,28$, 39-41]. Due to the prolonged incubation during which the cells are exposed to both pathogens (bacteria and viruses), it cannot be excluded that viral infection enhances bacterial binding also in our experimental setting. Such augmented bacterial attachment and concomitant enhanced recognition might also explain an increased inflammatory response. In a second set of experiments, we therefore investigated if the altered inflammatory response of co-stimulated cells required the presence of bacteria during viral infection.

Cells were pre-exposed to bacteria for $24 \mathrm{~h}$, after which cell layers were washed thoroughly with PBS and infected with RSV. This pre-exposure of cells to $H$. influenzae was sufficient to synergistically increase RSV- induced IL-6 release at all assessed time points. Preexposure also increased IL-8 release after subsequent infection with RSV, with the interaction reaching statistical significance at $72 \mathrm{~h}$ after infection and a trend towards statistical significance at the earlier time points (24 h: $p=0.077 ; 48$ h: $p=0.089$; Fig. 2d).

In cells pre-exposed to $P$. aeruginosa before RSVinfection, we only detected a small, yet statistically significant synergistic effect on IL-6 production $24 \mathrm{~h}$ after infection (mean increase over additive effect $8 \% \pm 2 \%, p=$ 0.002 ), but not at the later time points (Fig. $2 \mathrm{~b}$ ). IL- 8 secretion in response to RSV, however, was still synergistically enhanced after pre-exposure of cells to $P$. aeruginosa at $72 \mathrm{~h}$ after infection (Fig. 2e). In line with the results obtained from a continuous exposure to bacteria, preexposure of cells to heat-inactivated preparations of $S$. pneumoniae did not significantly affect cytokine release after RSV infection (Fig. $2 \mathrm{c}$ and f). As for the continuous exposure protocol, also during the pre-exposure protocol there was no evidence for a significant effect of the treatments on cell viability (Additional file 1: Figure S1C).

Taken together, these results indicate that pre-exposure of cells with NT $H$. influenzae, is sufficient to potentiate RSV-induced cytokine release and that continuous presence of bacteria is not required. The increased inflammatory response of cells pre-exposed to NT $H$. influenzae was thus unlikely to be triggered by enhanced bacterial attachment to the cells.

\section{Influence of previous exposure to bacteria on RSV-induced IL- 6 production by primary bronchial epithelial cells}

We next sought to confirm our findings in primary bronchial epithelial cells (pBECs). Therefore, bronchial epithelial cells were isolated from seven non-smoking individuals without chronic respiratory diseases such as COPD, asthma or cystic fibrosis (median age 67 years; range 55-78 years). Presence of chronic respiratory diseases was excluded based on medical history, pulmonary function tests and imaging. The cells were treated with suspensions of heat-inactivated bacteria and subsequently infected with RSV according to the pre-exposure protocol described in the Methods section of this article.

Cytokine release, particularly in response to RSV infection, varied considerably between cells from different donors (Table 1).

In order to account for inter-individual variability, results in Fig. 3 are expressed as percent changes relative to a calculated additive effect (i.e., relative to the sum of cytokine concentrations released in response to each pathogen alone) for each donor. Pre-exposure to $H$. influenzae increased RSV-induced IL-6 release by cells from four out of seven donors above this additive effect (Fig. 3a). Likewise, pre-exposure to $P$. aeruginosa synergistically enhanced the 


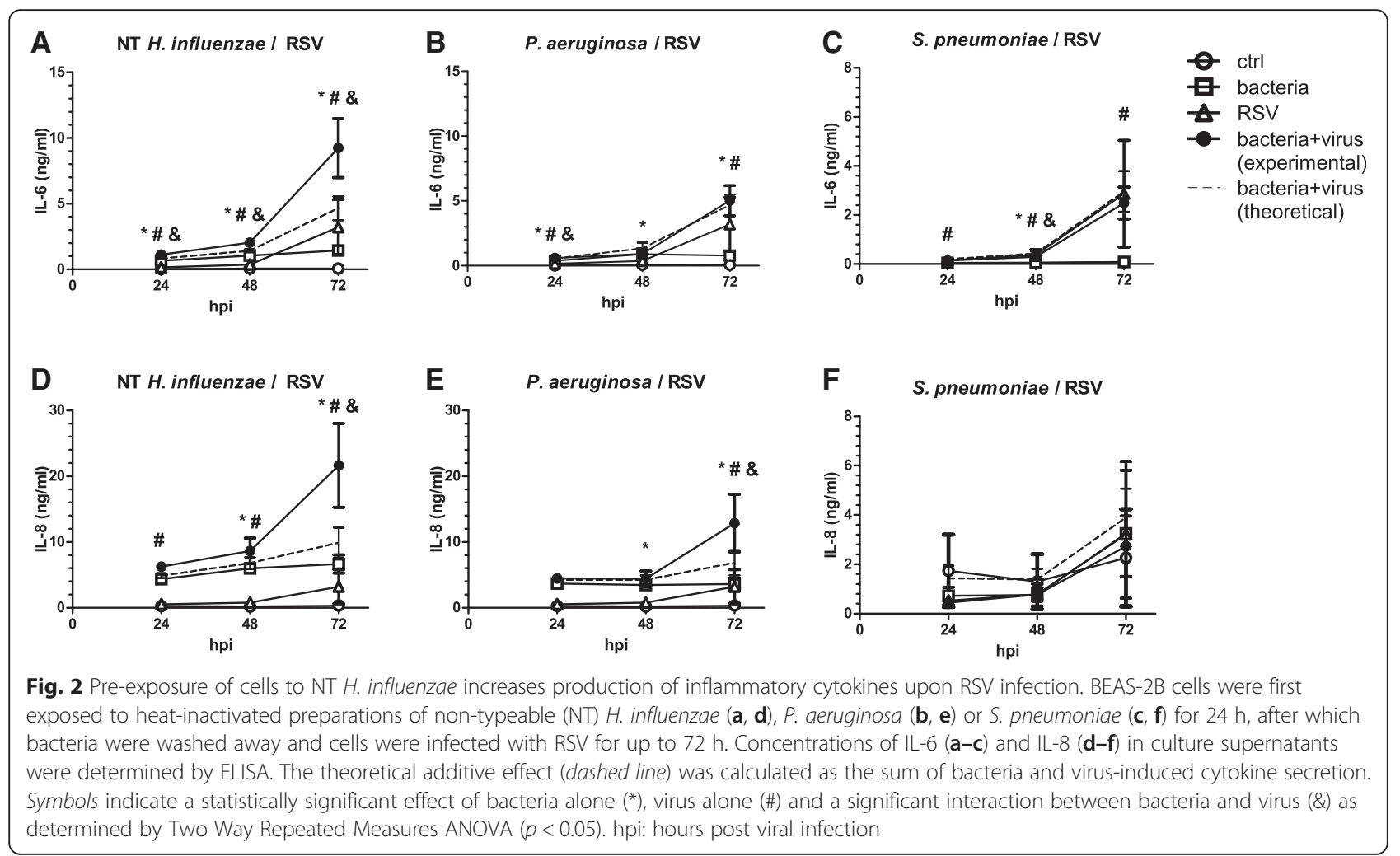

IL-6 release following RSV infection in four out of seven donors, with a trend towards statistical significance $72 \mathrm{~h}$ after infection ( $p=0.09$, Fig. 3b). Moreover, and also in line with the results obtained in BEAS-2B cells, S. pneumoniae did not further increase IL-6 release after RSV-infection in pBECs (Fig. 3c). In contrast, however, pre-exposure of pBECs to either bacterial species did not significantly affect virus-induced IL-8 secretion (data not shown).

Up to $48 \mathrm{~h}$ after viral infection, there was no effect of the treatments on metabolic activity of pBECs; Seventy-two hours after infection, cell viability was modestly decreased in virus-infected cells, yet there were no differences between cells pre-treated with the different bacteria that would explain altered cytokine secretion (Additional file 1: Figure S1D).
Enhanced release of inflammatory mediators is not linked to enhanced viral replication

Exposure to bacterial pathogens has previously been suggested to enhance viral attachment and replication in lung epithelial cells [36, 42]. We therefore tested if the enhanced inflammatory response of BEAS-2B cells towards RSV after pre-exposure with bacteria was due to enhanced viral replication. Neither intracellular viral RNA levels (Fig. 4a) nor the release of infectious progeny (Fig. 4b) was significantly altered when cells were pre-exposed to either of the three bacteria used in this study. Nevertheless, viral replication seemed at least indirectly to be required to potentiate cytokine release, since $H$. influenzae in combination with UV-inactivated virus did not cause increased secretion of IL-6 (Additional file 1: Figure S1E). In agreement with this, synergy between the pathogens was most pronounced after

Table 1 IL-6 release by pBECs pre-exposed to heat-inactivated bacteria and subsequently infected with RSV

\begin{tabular}{|c|c|c|c|c|c|c|}
\hline & \multicolumn{2}{|l|}{24 hpi } & \multicolumn{2}{|l|}{48 hpi } & \multicolumn{2}{|l|}{72 hpi } \\
\hline & - RSV & $+\mathrm{RSV}$ & - RSV & $+\mathrm{RSV}$ & -RSV & $+\mathrm{RSV}$ \\
\hline ctrl & $6.1 \pm 1.1$ & $179.1 \pm 77.2$ & $8.4 \pm 2.6$ & $208.5 \pm 83.3$ & $6.6 \pm 1.8$ & $234.3 \pm 91.6$ \\
\hline +hiNTHI & $8.4 \pm 1.6$ & $206.8 \pm 88.0$ & $11.4 \pm 2.6$ & $258.7 \pm 116.3$ & $10.3 \pm 2.7$ & $324.2 \pm 147.3$ \\
\hline +hiPA & $19.5 \pm 14.9$ & $225.0 \pm 123.0$ & $21.4 \pm 16.3$ & $288.7 \pm 120.6$ & $18.6 \pm 13.9$ & $335.3 \pm 139.7$ \\
\hline +hiSP & $4.5 \pm 0.9$ & $177.8 \pm 74.8$ & $6.0 \pm 1.7$ & $210.0 \pm 88.0$ & $6.2 \pm 1.6$ & $238.7 \pm 100.1$ \\
\hline
\end{tabular}

Values are given in $\mathrm{pg} / \mathrm{ml}$ and represent the mean $\pm \operatorname{SEM}(n=7)$. hpi: hours post (viral) infection, hi heat-inactivated, NTHI non-typeable $H$. influenzae, $P A P$. aeruginosa, SP S. pneumoniae, RSV respiratory syncytial virus 

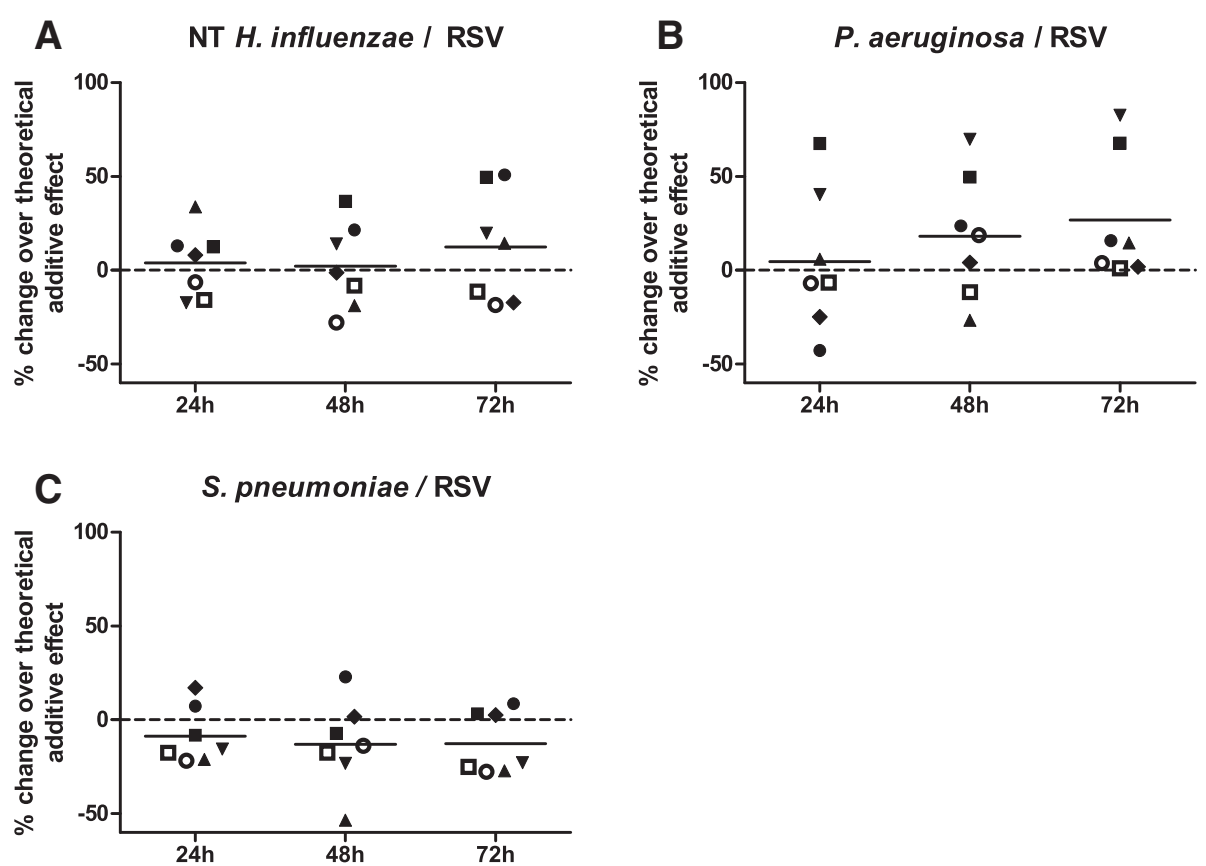

Fig. 3 Exposure of pBECs to NT H. influenzae or P. aeruginosa enhances IL-6 release. PBECS of seven donors were pre-exposed to heat-inactivated preparations of non-typeable (NT) H. influenzae (a), P. aeruginosa (b), or S. pneumoniae (c) for 24 h, after which bacteria were washed away and cells were infected with RSV for up to $72 \mathrm{~h}$. IL-6 levels in culture supernatants 24,48 and $72 \mathrm{~h}$ after viral infection were determined by ELISA. Due to considerable inter-individual variation in absolute cytokine levels, data are shown as relative changes of experimentally determined cytokine concentrations over the theoretical additive effect for each donor. Results obtained using cells from each donor are denoted with the same symbol in all datasets. hpi: hours post viral infection

cells mounted a cytokine response against the virus itself, i.e., at $48 \mathrm{~h}$ after viral infection and later.

To test if exaggerated inflammation was linked to increased expression of key PRRs involved in the recognition of bacterial and/or viral structures, we next measured mRNA levels of TLR2, TLR3, TLR4 and RIG-I. However, there was no significant interaction between bacteria and viruses on the expression levels of any of these genes (Additional file 1: Figure S2).

\section{Changes in the virus-induced inflammatory response after bacterial pre-exposure are species-specific}

Because of the pathogen-specificity we observed when investigating different bacteria in combination with RSV, we next evaluated the inflammatory response of bacterially challenged epithelial cells during infection with different viruses. Next to RSV, rhinoviruses, influenza viruses and specific adenoviruses are among the most frequently detected respiratory viral pathogens $[5,43]$. Since the influence of bacterial exposure on infection with human rhinovirus has already been the subject of previous studies $[36,42]$, we now assessed combinations of different bacteria with influenza $B$ virus and a type 2 human adenovirus.

In our hands, infection with influenza B virus only induced modest IL-6 release (Fig. 5 a-c). Although we found a statistically significant interaction between $H$. influenzae and influenza $B$ virus (measured cytokine levels lower than the calculated additive effect 24 and $72 \mathrm{~h}$ after infection), as well as between $P$. aeruginosa and influenza B (measured cytokine levels lower than the calculated additive effect at all time points), co-stimulated cells still released cytokines at levels comparable to those of cells stimulated with bacteria only.

Human adenovirus on the other hand did not induce IL6 production by itself, but significantly reduced cytokine release induced by the different bacteria. When compared to the additive effect of the pathogens, stimulation of cells with adenovirus after bacterial exposure reduced IL-6 release at 72 h by $57 \% \pm 6 \%$ in combination with NT $H$. influenzae (Fig. 5d) and $68 \% \pm 4 \%$ in combination with $P$. aeruginosa (Fig. 5e). For IL-8, there was a significant interaction between all three bacteria in combination with human adenovirus $72 \mathrm{~h}$ after viral infection. Measured IL-8 levels were on average $39 \% \pm 9 \%$ (for NT H. influenzae), $42 \% \pm 4 \%$ (for P. aeruginosa) and $83 \% \pm 2 \%$ (for S. pneumoniae) below the additive effect of these pathogens.

In summary, the effect of subsequent challenges with bacteria and viruses on release of inflammatory mediators was not only dependent on the bacterial species used, but also virus-dependent. 


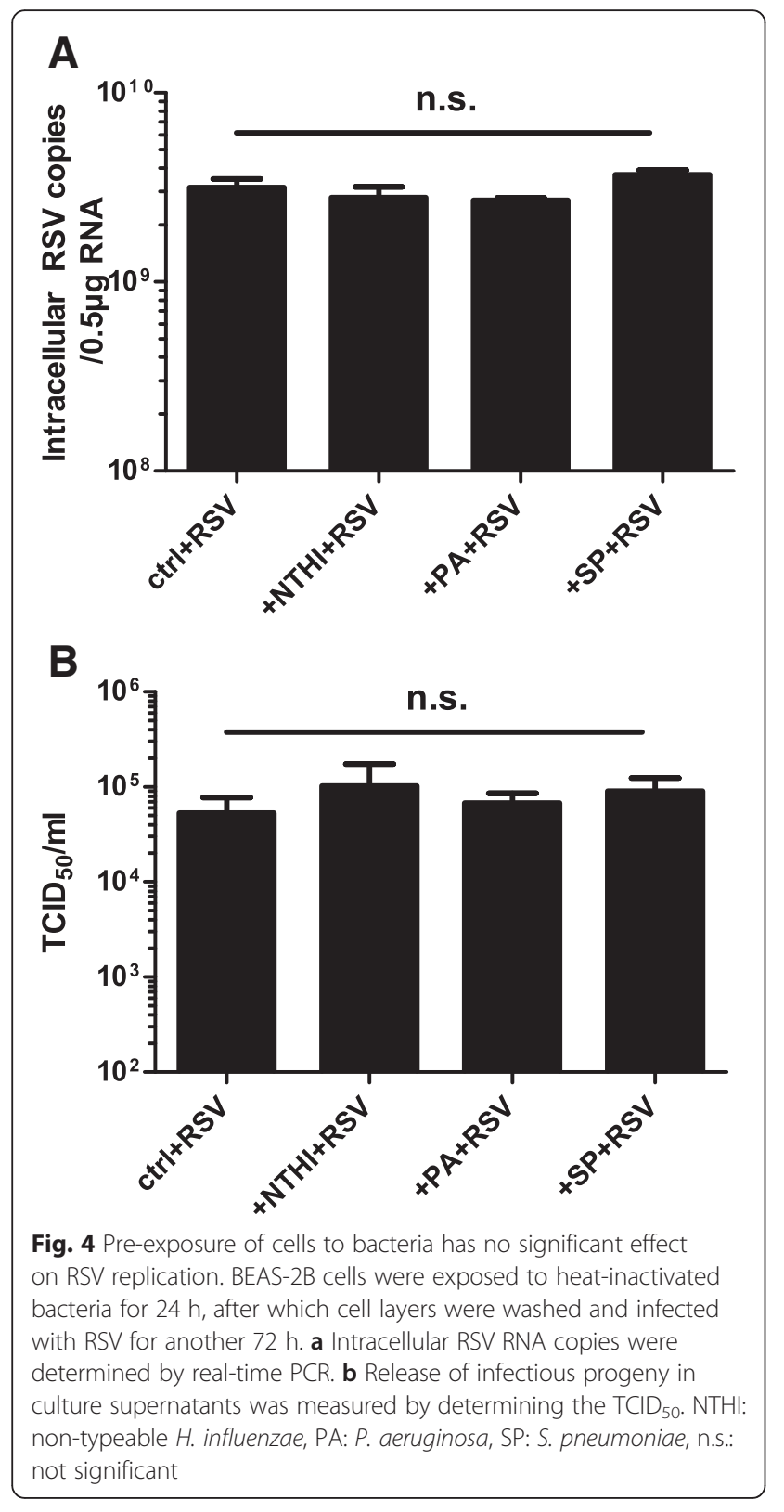

\section{Discussion}

$H$. influenzae is the most commonly found PPM in the lower respiratory tract of COPD patients. We here demonstrate that exposure of the bronchial epithelial cell line BEAS-2B to heat-inactivated $H$. influenzae significantly augments RSV-induced release of the proinflammatory cytokines IL-6 and IL-8. H. influenzae has previously been described to enhance the secretion of IL-8 in response to certain strains of another major respiratory virus, human rhinovirus (HRV), by upregulating expression of TLR3 [42]. In our experimental model of bacterial exposure and RSV-infection, the synergy between heat-inactivated $H$. influenzae and RSV on the release of pro-inflammatory cytokines was not reflected in the expression levels of TLR3, or other pattern recognition receptors (PRRs) relevant for the detection of RSV and/or $H$. influenzae [44-47].

Increased bacterial or viral binding is considered a major feature in the pathogenesis of polymicrobial infections. RSV infection has previously been described to promote fimbriae-mediated attachment of $H$. influenzae to epithelial cells [41, 48]. However, considering that the proinflammatory effects of pre-exposure to heat-inactivated $H$. influenzae were sustained even when unbound bacteria were washed away prior to RSV infection, the increased release of IL- 6 and IL- 8 is most likely not a consequence of greater bacterial binding. Conversely, exposure of lung epithelial cells to $H$. influenzae has been shown to increase the cells' susceptibility to secondary infection with major group HRV by upregulating their cellular entry receptor, ICAM-1 [36, 42]. Although neutralizing antibodies for ICAM-1 can reduce RSV infection in vitro, it is not the main functional receptor for this virus $[49,50]$. Correspondingly, the exaggerated inflammation we observed in our model was not linked to increased viral endpoint titers nor increased levels of intracellular viral RNA, suggesting alterations in intra- or intercellular signaling rather than a generalized increase in viral replication as a cause. Nevertheless, viral replication was at least indirectly required, since UV-inactivated virus did not further increase the secretion of inflammatory cytokines in our experimental model. Interestingly, treatment of epithelial cells with heat-killed $H$. influenzae can reduce bacterial and fungal burden after secondary infection with several pathogens, and also limit influenza virus replication in a mouse model of influenza virus pneumonia [51, 52]. Effectiveness against other viruses has yet to be evaluated, but was not evident for RSV in our model.

Similar to $H$. influenzae, also $P$. aeruginosa elicited a strong increase in the secretion of pro-inflammatory cytokines IL- 6 and IL-8, and like $H$. influenzae, potentiated RSV-induced cytokine release. However, in BEAS-2B cells, continuous presence of $P$. aeruginosa during viral infection was required to observe a sustained synergistic effect on IL- 6 release. $P$. aeruginosa and RSV have been described to interact directly and RSV has hence been suggested as a coupling agent between bacteria and cells, thus enhancing bacterial attachment [53]. Such an interaction might explain the diverging results we obtained using different exposure protocols.

The third bacterial pathogen we investigated in this study was S. pneumoniae, a Gram-positive opportunistic pathogen of the respiratory tract. In our experimental setting, heat-inactivated preparations of $S$. pneumoniae did not increase secretion of IL-6 or IL-8. This lack of an epithelial reaction towards $S$. pneumoniae might be attributable to the fact that we used heat-inactivated preparations of bacteria, preventing the expression of important virulence 


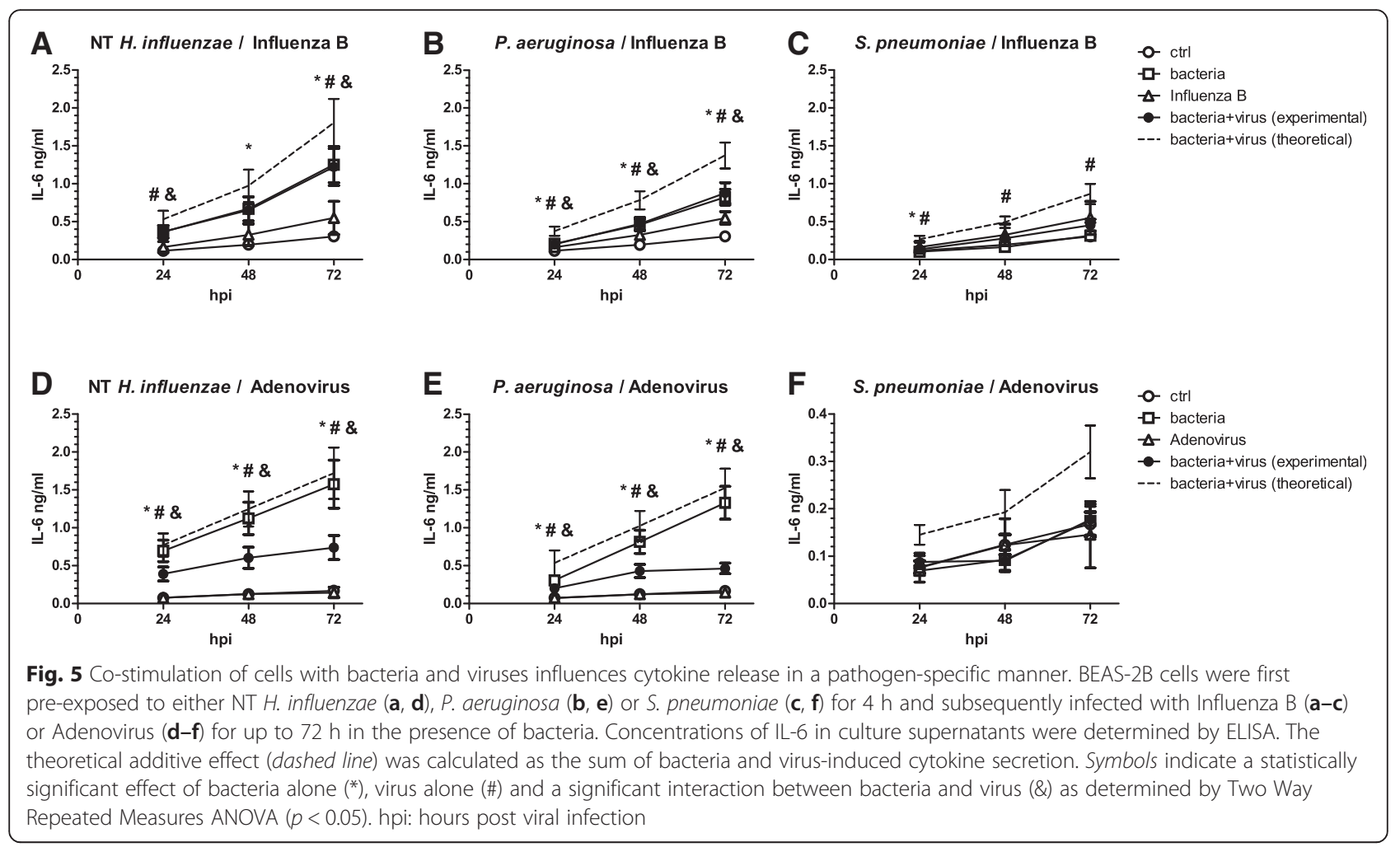

factors. Also, we did not observe a consistent significant interaction between S. pneumoniae and RSV in our model in terms of eliciting an inflammatory response. Importantly, RSV has recently been found to directly interact with S. pneumoniae [54]. Bacterial binding to the viral G protein triggered profound alterations in the bacterial transcriptome and lead to increased expression of a set of virulence factors. Unfortunately, in our experimental setting inactivation of bacteria was inevitable to prevent bacterial overgrowth and synergistic effects of $S$. pneumoniae and RSV might therefore be obscured. Altered bacterial virulence due to direct interactions between pathogens adds another layer of complexity to the study of polymicrobial infections.

Our experiments in pBECs revealed considerable interindividual differences between cells from different donors, not only in terms of absolute cytokine concentrations, but also with respect to the effect of bacterial exposure on subsequent infection. Although we aimed to include pBEC donors of a relatively homogenous group in terms of age, smoking-status and the absence of COPD, asthma and cystic fibrosis as underlying pulmonary diseases, differences that arise due to their clinical background or the isolation procedure cannot fully be excluded as a source of variability. Notably, cytokine release was evidently lower in primary cells than in BEAS-2B cells, particularly in response to bacteria. This less responsive phenotype might contribute to the differences we observed between primary cells and the immortalized cell line. Nonetheless, at 72hpi, results obtained with cells from four out of seven donors were in line with the data obtained in BEAS-2B cells, showing a more than additive effect of pre-exposure with $H$. influenzae or $P$. aeruginosa and RSV infection.

The effect of an exposure to bacteria prior to viral infection on cellular inflammatory responses was not only dependent on the bacterial species, but was also virusspecific. Cells exposed to bacteria and subsequently infected with influenza B still released cytokine levels comparable to those of cells exposed to bacteria alone. Even though secondary bacterial infection is a major contributor to influenza virus pathology the reverse order of sequential infections does not seem to have such detrimental effects [34]. This is in line with previous data by Lee et al., who demonstrated a lack of effect on the course of the disease when mice were exposed to $H$. influenzae type b before an influenza challenge, despite a strong lethal synergism when mice were infected in the reverse order [55]. Application of $H$. influenzae lysates can even confer a temporary protection against subsequent influenza infection by boosting local innate responses [52].

In contrast, cytokine levels produced by cells infected with adenovirus after an initial bacterial exposure were significantly reduced. Decreased levels of IL-6 and IL-8 after exposure to bacterial stimuli in combination with adenovirus might be attributed to the adenoviral proteins E1A and $\mathrm{E} 1 \mathrm{~B}$, which have previously been reported to reduce 
the induction of IL- 6 in response to bacterial and inflammatory stimuli in human epithelial cells $[56,57]$.

Using an in vitro model of bronchial epithelial cells allowed us to investigate pathogen specific interactions in a controlled environment. Being the first tissue to be exposed to infectious particles, the airway epithelium is crucial for initiating a first immune response. However, the possibilities to mimic a chronic exposure to bacteria, as would be the case during a bacterial colonization of the lungs, are limited in vitro. Therefore, more studies are needed to examine, for example, the impact of immune cells and the development of tolerance in this context. Extrapolating biological significance from the magnitude of an effect observed in vitro may be difficult. In a model of bacterial co-colonization, Ratner et al. showed that interactions of pathogens on the release of cytokines in vitro which were in a similar order of magnitude as the ones we observed in our study, could indeed translate to a biologically relevant effect in vivo [58].

Even though culture-dependent techniques usually only revealed a limited number of bacterial genera in the lower respiratory tract of colonized individuals, molecular techniques suggest that the lung microbiota is in fact far more complex. Furthermore, changes in the lung microbiome in asthma and COPD have been reported in several studies [59-61]; particularly pathogenic proteobacteria, such as $H$. influenzae, were more frequently found in the lungs of patients suffering from these diseases than in control subjects. It can be assumed that not only the presence of certain bacterial species, but also the composition of the local microbiota in the respiratory tract affects the response towards viral pathogens. In view of the pathogen-specific effects we observed in our study, it would therefore be interesting to expand this concept further towards a more complex representation of the lung microbiome in health and disease.

\section{Conclusions}

We show that pre-exposure of airway epithelial cells to heat-inactivated NT $H$. influenzae and $P$. aeruginosa aggravates the production of pro-inflammatory cytokines in response to subsequent infection with RSV, but not influenza B virus or adenovirus. Taken together, our data provide experimental evidence for the pleiotropic effects of microbial interactions on pulmonary inflammation. If these findings can be translated into the clinical setting, it might enable clinicians to identify patients at high risk for developing more severe viral infections on the basis of their bacteriological status.

\section{Additional file}

Additional file 1: Supplemental information. (ZIP $83 \mathrm{~kb}$ )

\section{Acknowledgements}

The authors would like to thank Danny Goudkade, MD (Department of Pathology, Maastricht University Medical Center) for his help in collecting the lung tissue used for isolation of pBECs, as well as Dinette Agterhuis, MD (Department of Respiratory Medicine, Maastricht University Medical Center) for gathering the data on donor characteristics.

Part of the work described in this manuscript has been presented as an abstract at the Annual Meeting of the European Respiratory Society 2015 (European Respiratory Journal Sep 2015, 46 (suppl 59) DOl: 10.1183/ 13993003.congress-2015.PA2604).

\section{Authors' contributions}

CB designed and performed experiments, analyzed data and drafted the manuscript. FG designed experiments, interpreted data and revised the manuscript. AH performed experiments and analyzed data. MD, PS and EW interpreted data and revised the manuscript. GR and FS conceived and designed the study, interpreted data and revised the manuscript. All authors read and approved the final version of the manuscript.

\section{Competing interests}

The authors declare that they have no competing interests.

\section{Author details}

${ }^{1}$ Department of Medical Microbiology, School of Nutrition and Translational Research in Metabolism (NUTRIM), Maastricht University, Maastricht, The Netherlands. ${ }^{2}$ Department of Respiratory Medicine, Maastricht University Medical Center, Maastricht, The Netherlands. ${ }^{3}$ Department of Medical Microbiology \& Infection Control, VU University Medical Center, Amsterdam, The Netherlands. ${ }^{4}$ P.O. Box 5800, 6202AZ Maastricht, The Netherlands. ${ }^{5}$ Department of Cell Biology and Immunology, University of North Texas Health Science Center (UNT Health Science Center), Fort Worth, TX, USA.

Received: 22 January 2016 Accepted: 24 May 2016

Published online: 03 June 2016

\section{References}

1. Sapey E, Stockley RA. COPD exacerbations.2: aetiology. Thorax. 2006;61:250-8.

2. MacDonald M, Korman T, King P, Hamza K, Bardin P. Exacerbation phenotyping in chronic obstructive pulmonary disease. Respirology. 2013; 18:1280-1.

3. Mallia P, Message SD, Gielen V, Contoli M, Gray K, Kebadze T, Aniscenko J, LazaStanca V, Edwards MR, Slater L. Experimental rhinovirus infection as a human model of chronic obstructive pulmonary disease exacerbation. Am J Respir Crit Care Med. 2011;183:734-42.

4. Message SD, Laza-Stanca V, Mallia P, Parker HL, Zhu J, Kebadze T, Contoli M, Sanderson G, Kon OM, Papi A. Rhinovirus-induced lower respiratory illness is increased in asthma and related to virus load and Th1/2 cytokine and IL-10 production. Proc Natl Acad Sci U S A. 2008;105:13562-7.

5. Rohde G, Wiethege A, Borg I, Kauth M, Bauer T, Gillissen A, Bufe A, Schultze Werninghaus $\mathrm{G}$. Respiratory viruses in exacerbations of chronic obstructive pulmonary disease requiring hospitalisation: a case-control study. Thorax. 2003:58:37-42

6. Zwaans WA, Mallia P, van Winden ME, Rohde GG. The relevance of respiratory viral infections in the exacerbations of chronic obstructive pulmonary disease-a systematic review. J Clin Virol. 2014;61:181-8.

7. Monso E, Rosell A, Bonet G, Manterola J, Cardona PJ, Ruiz J, Morera J. Risk factors for lower airway bacterial colonization in chronic bronchitis. Eur Respir J. 1999:13:338-42.

8. Cabello H, Torres A, Celis R, El-Ebiary M, Puig de la Bellacasa J, Xaubet A, Gonzalez J, Agusti C, Soler N. Bacterial colonization of distal airways in healthy subjects and chronic lung disease: a bronchoscopic study. Eur Respir J. 1997;10:1137-44.

9. Zalacain R, Sobradillo V, Amilibia J, Barron J, Achotegui V, Pijoan Jl, Llorente $J$. Predisposing factors to bacterial colonization in chronic obstructive pulmonary disease. Eur Respir J. 1999;13:343-8.

10. Rosell A, Monso E, Soler N, Torres F, Angrill J, Riise G, Zalacain R, Morera J,Torres A. Microbiologic determinants of exacerbation in chronic obstructive pulmonary disease. Arch Intern Med. 2005;165:891-7.

11. Lyczak JB, Cannon CL, Pier GB. Lung infections associated with cystic fibrosis. Clin Microbiol Rev. 2002;15:194-222. 
12. Huang YJ, Nelson CE, Brodie EL, Desantis TZ, Baek MS, Liu J, Woyke T, Allgaier M, Bristow J, Wiener-Kronish JP. Airway microbiota and bronchial hyperresponsiveness in patients with suboptimally controlled asthma. J Allergy Clin Immunol. 2011;127:372-81. e371-373.

13. Wood LG, Simpson JL, Hansbro PM, Gibson PG. Potentially pathogenic bacteria cultured from the sputum of stable asthmatics are associated with increased 8isoprostane and airway neutrophilia. Free Radic Res. 2010;44:146-54.

14. Patel IS, Seemungal TA, Wilks M, Lloyd-Owen SJ, Donaldson GC, Wedzicha JA. Relationship between bacterial colonisation and the frequency, character, and severity of COPD exacerbations. Thorax. 2002;57:759-64.

15. Soler N, Ewig S, Torres A, Filella X, Gonzalez J, Zaubet A. Airway inflammation and bronchial microbial patterns in patients with stable chronic obstructive pulmonary disease. Eur Respir J. 1999;14:1015-22.

16. Bresser $P$, Out $T A$, van Alphen $L$, Jansen HM, Lutter R. Airway inflammation in nonobstructive and obstructive chronic bronchitis with chronic haemophilus influenzae airway infection. Comparison with noninfected patients with chronic obstructive pulmonary disease. Am J Respir Crit Care Med. 2000;162:947-52.

17. Bhowmik A, Seemungal TA, Sapsford RJ, Wedzicha JA. Relation of sputum inflammatory markers to symptoms and lung function changes in COPD exacerbations. Thorax. 2000;55:114-20.

18. Seemungal TA, Harper-Owen R, Bhowmik A, Jeffries DJ, Wedzicha JA. Detection of rhinovirus in induced sputum at exacerbation of chronic obstructive pulmonary disease. Eur Respir J. 2000;16:677-83.

19. Seemungal T, Harper-Owen R, Bhowmik A, Moric I, Sanderson G, Message S, Maccallum P, Meade TW, Jeffries DJ, Johnston SL, Wedzicha JA. Respiratory viruses, symptoms, and inflammatory markers in acute exacerbations and stable chronic obstructive pulmonary disease. Am J Respir Crit Care Med. 2001;164:1618-23.

20. Wilkinson TM, Hurst JR, Perera WR, Wilks M, Donaldson GC, Wedzicha JA. Effect of interactions between lower airway bacterial and rhinoviral infection in exacerbations of COPD. Chest. 2006;129:317-24.

21. Papi A, Bellettato CM, Braccioni F, Romagnoli M, Casolari P, Caramori G, Fabbri LM, Johnston SL. Infections and airway inflammation in chronic obstructive pulmonary disease severe exacerbations. Am J Respir Crit Care Med. 2006;173:1114-21.

22. Bafadhel M, McKenna S, Terry S, Mistry V, Reid C, Haldar P, McCormick M, Haldar K, Kebadze T, Duvoix A, et al. Acute exacerbations of chronic obstructive pulmonary disease: identification of biologic clusters and their biomarkers. Am J Respir Crit Care Med. 2011;184:662-71.

23. Bandi V, Jakubowycz M, Kinyon C, Mason EO, Atmar RL, Greenberg SB, Murphy TF. Infectious exacerbations of chronic obstructive pulmonary disease associated with respiratory viruses and non-typeable Haemophilus influenzae. FEMS Immunol Med Microbiol. 2003;37:69-75.

24. Sajjan U, Wang Q, Zhao Y, Gruenert DC, Hershenson MB. Rhinovirus disrupts the barrier function of polarized airway epithelial cells. Am J Respir Crit Care Med. 2008;178:1271-81.

25. Patel J, Faden H, Sharma S, Ogra PL. Effect of respiratory syncytial virus on adherence, colonization and immunity of non-typable Haemophilus influenzae: implications for otitis media. Int J Pediatr Otorhinolaryngol. 1992; 23:15-23.

26. Sanford BA, Ramsay MA. Bacterial adherence to the upper respiratory tract of ferrets infected with influenza A virus. Proc Soc Exp Biol Med. 1987;185:120-8.

27. Ramphal R, Small PM, Shands Jr JW, Fischlschweiger W, Small Jr PA. Adherence of Pseudomonas aeruginosa to tracheal cells injured by influenza infection or by endotracheal intubation. Infect Immun. 1980;27:614-9.

28. Hament JM, Aerts PC, Fleer A, Van Dijk H, Harmsen T, Kimpen JL, Wolfs TF. Enhanced adherence of Streptococcus pneumoniae to human epithelial cells infected with respiratory syncytial virus. Pediatr Res. 2004;55:972-8.

29. Blevins LK, Wren JT, Holbrook BC, Hayward SL, Swords WE, Parks GD Alexander-Miller MA. Coinfection with Streptococcus pneumoniae negatively modulates the size and composition of the ongoing influenza-specific CD8(+) T cell response. J Immunol. 2014;193:5076-87.

30. Jamieson AM, Yu S, Annicelli CH, Medzhitov R. Influenza virus-induced glucocorticoids compromise innate host defense against a secondary bacterial infection. Cell Host Microbe. 2010;7:103-14.

31. Robinson KM, Choi SM, McHugh KJ, Mandalapu S, Enelow RI, Kolls JK, Alcorn JF. Influenza A exacerbates Staphylococcus aureus pneumonia by attenuating IL-1 beta production in mice. J Immunol. 2013;191:5153-9.

32. Robinson KM, McHugh KJ, Mandalapu S, Clay ME, Lee B, Scheller EV, Enelow RI,Chan YR, Kolls JK, Alcorn JF. Influenza A virus exacerbates Staphylococcus aureus pneumonia in mice by attenuating antimicrobial peptide production. J Infect Dis. 2014;209:865-75.

33. Lee B, Robinson KM, McHugh KJ, Scheller EV, Mandalapu S, Chen C, Di YP, Clay ME, Enelow Rl, Dubin PJ, Alcorn JF. Influenza-induced Type I Interferon Enhances Susceptibility to Gram-negative and Gram-positive Bacterial Pneumonia in Mice. Am J Physiol Lung Cell Mol Physiol. 2015;309:L158-67. ajplung 0033802014.

34. McCullers JA. The co-pathogenesis of influenza viruses with bacteria in the lung. Nat Rev Microbiol. 2014;12:252-62.

35. van Wetering $S$, van der Linden AC, van Sterkenburg MA, de Boer WI, Kuijpers AL, Schalkwijk J, Hiemstra PS. Regulation of SLPI and elafin release from bronchial epithelial cells by neutrophil defensins. Am J Physiol Lung Cell Mol Physiol. 2000;278:L51-8.

36. Gulraiz F, Bellinghausen C, Bruggeman CA, Stassen FR. Haemophilus influenzae increases the susceptibility and inflammatory response of airway epithelial cells to viral infections. FASEB J. 2015;29:849-58.

37. Hierholzer JC, Killington RA: Virus Isolation and Quantitation. In Virology Methods Manual. Edited by Mahy B, Kangro H. London: Academic Press; 1996.

38. Sha Q, Truong-Tran AQ, Plitt JR, Beck LA, Schleimer RP. Activation of airway epithelial cells by toll-like receptor agonists. Am J Respir Cell Mol Biol. 2004; 31:358-64.

39. Wang JH, Kwon HJ, Jang YJ. Rhinovirus enhances various bacterial adhesions to nasal epithelial cells simultaneously. Laryngoscope. 2009;119:1406-11.

40. Avadhanula V, Rodriguez CA, Devincenzo JP, Wang Y, Webby RJ, Ulett GC Adderson EE. Respiratory viruses augment the adhesion of bacterial pathogens to respiratory epithelium in a viral species- and cell typedependent manner. J Virol. 2006;80:1629-36.

41. Jiang Z, Nagata N, Molina E, Bakaletz LO, Hawkins H, Patel JA. Fimbria-mediated enhanced attachment of nontypeable Haemophilus influenzae to respiratory syncytial virus-infected respiratory epithelial cells. Infect Immun. 1999:67:187-92.

42. Sajjan US, Jia Y, Newcomb DC, Bentley JK, Lukacs NW, LiPuma JJ, Hershenson MB. H. influenzae potentiates airway epithelial cell responses to rhinovirus by increasing ICAM-1 and TLR3 expression. FASEB J. 2006;20: $2121-3$.

43. Hosseini SS, Ghasemian E, Jamaati H, Tabaraie B, Amini Z, Cox K. Association between respiratory viruses and exacerbation of COPD: a case-control study. Infect Dis (Lond). 2015;47:523-9.

44. Wang X, Moser C, Louboutin JP, Lysenko ES, Weiner DJ, Weiser JN, Wilson JM. Toll-like receptor 4 mediates innate immune responses to Haemophilus influenzae infection in mouse lung. J Immunol. 2002;168:810-5.

45. Kurt-Jones EA, Popova L, Kwinn L, Haynes LM, Jones LP, Tripp RA, Walsh EE, Freeman MW, Golenbock DT, Anderson L, Finberg RW. Pattern recognition receptors TLR4 and CD14 mediate response to respiratory syncytial virus. Nat Immunol. 2000;1:398-401.

46. Murawski MR, Bowen GN, Cerny AM, Anderson L, Haynes LM, Tripp RA, Kurt Jones EA, Finberg RW. Respiratory syncytial virus activates innate immunity through Toll-like receptor 2. J Virol. 2009;83:1492-500.

47. Shuto T, Xu H, Wang B, Han J, Kai H, Gu XX, Murphy TF, Lim DJ, Li JD. Activation of NF-kappa B by nontypeable Hemophilus influenzae is mediated by toll-like receptor 2-TAK1-dependent NIK-IKK alpha/beta-I kappa $\mathrm{B}$ alpha and MKK3/6-p38 MAP kinase signaling pathways in epithelial cells. Proc Natl Acad Sci U S A. 2001;98:8774-9.

48. Raza MW, Ogilvie MM, Blackwell CC, Stewart J, Elton RA, Weir DM. Effect of respiratory syncytial virus infection on binding of Neisseria meningitidis and Haemophilus influenzae type $b$ to a human epithelial cell line (HEp-2). Epidemiol Infect. 1993;110:339-47.

49. Behera AK, Matsuse H, Kumar M, Kong X, Lockey RF, Mohapatra SS. Blocking intercellular adhesion molecule-1 on human epithelial cells decreases respiratory syncytial virus infection. Biochem Biophys Res Commun. 2001; 280:188-95.

50. Mastrangelo P, Hegele RG. RSV fusion: time for a new model. Viruses. 2013; 5:873-85.

51. Evans SE, Scott BL, Clement CG, Larson DT, Kontoyiannis D, Lewis RE, Lasala PR, Pawlik J, Peterson JW, Chopra AK, et al. Stimulated innate resistance of lung epithelium protects mice broadly against bacteria and fungi. Am J Respir Cell Mol Biol. 2010;42:40-50.

52. Tuvim MJ, Evans SE, Clement CG, Dickey BF, Gilbert BE. Augmented lung inflammation protects against influenza A pneumonia. PLoS One. 2009;4:e4176. 
53. Van Ewijk BE, Wolfs TF, Aerts PC, Van Kessel KP, Fleer A, Kimpen JL, Van der Ent CK. RSV mediates Pseudomonas aeruginosa binding to cystic fibrosis and normal epithelial cells. Pediatr Res. 2007;61:398-403.

54. Smith CM, Sandrini S, Datta S, Freestone P, Shafeeq S, Radhakrishnan P. Williams G, Glenn SM, Kuipers OP, Hirst RA, et al. Respiratory syncytial virus increases the virulence of Streptococcus pneumoniae by binding to penicillin binding protein 1a. A new paradigm in respiratory infection. Am J Respir Crit Care Med. 2014;190:196-207.

55. Lee LN, Dias P, Han D, Yoon S, Shea A, Zakharov V, Parham D, Sarawar SR. A mouse model of lethal synergism between influenza virus and Haemophilus influenzae. Am J Pathol. 2010;176:800-11.

56. van den Berg A, Snoek M, Jansen HM, Lutter R. E1A expression dysregulates IL-8 production and suppresses IL-6 production by lung epithelial cells. Respir Res. 2005;6:111.

57. Janaswami PM, Kalvakolanu DV, Zhang Y, Sen GC. Transcriptional repression of interleukin-6 gene by adenoviral E1A proteins. J Biol Chem. 1992;267: 24886-91.

58. Ratner AJ, Lysenko ES, Paul MN, Weiser JN. Synergistic proinflammatory responses induced by polymicrobial colonization of epithelial surfaces. Proc Natl Acad Sci U S A. 2005;102:3429-34.

59. Sze MA, Dimitriu PA, Hayashi S, Elliott WM, McDonough JE, Gosselink JV, Cooper J, Sin DD, Mohn WW, Hogg JC. The lung tissue microbiome in chronic obstructive pulmonary disease. Am J Respir Crit Care Med. 2012;185: 1073-80.

60. Erb-Downward JR, Thompson DL, Han MK, Freeman CM, McCloskey L, Schmidt LA, Young VB, Toews GB, Curtis $J$, Sundaram B.. Analysis of the lung microbiome in the "healthy" smoker and in COPD. PLoS One. 2011;6: e16384.

61. Hilty M, Burke C, Pedro H, Cardenas P, Bush A, Bossley C, Davies J, Ervine A, Poulter L, Pachter L, et al. Disordered microbial communities in asthmatic airways. PLoS One. 2010;5:e8578.

\section{Submit your next manuscript to BioMed Central and we will help you at every step:}

- We accept pre-submission inquiries

- Our selector tool helps you to find the most relevant journal

- We provide round the clock customer support

- Convenient online submission

- Thorough peer review

- Inclusion in PubMed and all major indexing services

- Maximum visibility for your research

Submit your manuscript at www.biomedcentral.com/submit

C Biomed Central 